\title{
SOX2-silenced squamous cell carcinoma: a highly malignant form of esophageal cancer with SOX2 promoter hypermethylation
}

\author{
Ritsuko Maehara ${ }^{1,2}$, Kohei Fujikura ${ }^{1}$, Kengo Takeuchi ${ }^{3,4}$, Masayuki Akita ${ }^{1}$, \\ Shiho Abe-Suzuki ${ }^{1}$, Jana Karbanová ${ }$, Denis Corbeil ${ }^{5}$, Tomoo Itoh ${ }^{1}$, Yoshihiro Kakeji ${ }^{2}$ and \\ Yoh Zen ${ }^{1}$ \\ ${ }^{1}$ Department of Diagnostic Pathology, Kobe University Graduate School of Medicine, Kobe, Japan; \\ ${ }^{2}$ Department of Gastrointestinal Surgery, Kobe University Graduate School of Medicine, Kobe, Japan; \\ ${ }^{3}$ Division of Pathology, The Cancer Institute, Japanese Foundation for Cancer Research, Tokyo, Japan; \\ ${ }^{4}$ Pathology Project for Molecular Targets, The Cancer Institute, Japanese Foundation for Cancer Research, \\ Tokyo, Japan and ${ }^{5}$ Tissue Engineering Laboratories (BIOTEC), Technische Universität Dresden, Dresden, \\ Germany
}

\begin{abstract}
This study originally aimed to investigate whether the overexpression of SOX2 is associated with the poor prognosis of patients with squamous cell carcinoma of the esophagus. However, we unexpectedly found that esophageal squamous cell carcinomas completely lacking SOX2 expression showed distinct pathologic features and highly aggressive clinical courses. The study cohort consisted of 113 consecutive patients with esophageal squamous cell carcinoma who underwent surgical resection without neoadjuvant therapy. Immunostaining on tissue microarrays and whole sections revealed that $8 / 113(7 \%)$ cases were entirely negative for this transcriptional factor. SOX2-negative cancers were histologically less differentiated $(P=0.002)$ and showed higher pT and pStages $(P=0.003$ and 0.007 , respectively) than SOX2-positive cases. A remarkable finding was widespread lymphatic infiltration distant from the primary invasive focus, which was observed in 4 SOX2negative cancers $(50 \%)$, but none of the SOX2-positive cases. All separate dysplastic lesions observed in SOX2negative cases were also SOX2-negative. The negative expression of SOX2 appeared to be an independent poor prognostic factor $(\mathrm{OR}=7.05,95 \% \mathrm{Cl}=1.27-39.0)$. No mutations were identified in the coding or non-coding regions of SOX2. Fluorescent in situ hybridization did not show any copy-number variations in this gene. Since the SOX2 promoter contains an extensive CpG island, SOX2-negative cases underwent methylation-specific PCR, which disclosed promoter hypermethylation in all cases. In conclusion, SOX2-silenced squamous cell carcinomas of the esophagus appear to be a minor, but distinct form of malignancy characterized by extensive lymphatic invasion, a poor prognosis, and potential association with multiple SOX2-negative neoplastic lesions. The hypermethylation of the promoter region is seemingly a critical epigenetic event leading to SOX2 silencing. Modern Pathology (2018) 31, 83-92; doi:10.1038/modpathol.2017.112; published online 1 September 2017
\end{abstract}

Esophageal cancer is the sixth leading cause of cancer death and eighth most frequently diagnosed malignancy. ${ }^{1}$ Approximately $90 \%$ of esophageal cancers diagnosed worldwide are histologically squamous cell carcinomas. ${ }^{1}$ Despite recent advances in therapeutic modalities and treatment options, the 5 -year survival rate of esophageal squamous cell

Correspondence: Professor Y Zen, MD, PhD, FRCPath, Department of Diagnostic Pathology, Kobe University Graduate School of Medicine, Kobe 650-0017, Japan.

E-mail yohzen@med.kobe-u.ac.jp

Received 16 May 2017; revised 6 July 2017; accepted 6 July 2017; published online 1 September 2017 carcinomas remains less than $15 \% .^{1,2}$ Early esophageal cancers are typically asymptomatic and, thus, difficult to diagnose. Another factor causing a poor prognosis is that distant or nodal metastases may develop, even in cases in which primary tumors are restricted to the mucosal or submucosal tissue. ${ }^{2,3}$ Although molecular testing for gene fusions and amplifications has increasingly been used for other malignancies such as lung and breast cancers, marker-based stratification schemes are not currently available for squamous cell carcinomas of the esophagus. $^{2}$

SOX2, a SRY-related HMG-box transcription factor, has a critical role in the self-renewal and 
pluripotency of embryonic stem cells. ${ }^{4}$ The oncogenic role of SOX2 was initially described in $2009 .^{5}$ A peak in genomic amplification on chromosome 3q26.33 containing SOX2 was found in 6/30 (15\%) cases of esophageal squamous cell carcinomas. A fluorescence in situ hybridization analysis on tissue samples of an independent cohort of esophageal squamous cell carcinomas identified SOX2 amplification in $7 / 63(11 \%)$ patients. ${ }^{5}$ In vitro studies also revealed that SOX2 expression was essential for the proliferation of SOX2-overexpressing cell lines. ${ }^{5}$ Furthermore, the ectopic expression of $S O X 2$ cooperated with FOXE1 or FGFR2 transformed immortalized tracheobronchial epithelial cells. ${ }^{5}$ Based on these findings, SOX2 has been increasingly recognized as an oncogene and potential drug target in squamous cell carcinomas of the esophagus. ${ }^{6}$ The amplification and overexpression of $S O X 2$ were also demonstrated in squamous cell carcinomas of other organs (eg, the lungs, larynx, pharynx, uterine cervix, penis, and skin). ${ }^{7}$

The gene amplification and immunohistochemical expression of SOX2 are known to be moderately, but not entirely correlated. ${ }^{8}$ This study was performed based on our original hypothesis that the immunohistochemical overexpression of SOX2 may be associated with a poor prognosis in patients with esophageal squamous cell carcinoma. However, we unexpectedly found that esophageal cancers completely lacking SOX2 expression showed highly aggressive clinical courses. Their clinicopathologic features appeared to be distinct from those of SOX2retained tumors. The underlying molecular mechanisms of SOX2 silencing were also investigated by gene sequencing, fluorescent in situ hybridization, and methylation assays of the promoter region.

\section{Materials and methods}

\section{Case Selection and Tissue Samples}

This study was approved by the Ethics Committee of Kobe University Graduate School of Medicine. The study cohort consisted of 113 consecutive patients with esophageal squamous cell carcinoma who underwent surgical resection without neoadjuvant therapy at Kobe University Hospital between November 2005 and December 2015. Patients who received preoperative therapies before surgery were excluded because chemotherapy or radiotherapy may bias the evaluation of SOX2 expression. A possible example is that SOX2-positive cancers may become SOX2-negative after neoadjuvant therapy due to the cancer cells expressing SOX2 being eliminated. According to the protocol in our institute, the resected esophagus was entirely submitted for histologic examination in order to identify separate dysplastic lesions. Formalin-fixed paraffinembedded tissue was used for pathologic analyses and molecular studies.
Clinical information including patient prognoses was obtained from stored medical records and imaging. All patients were followed-up every 6 months after surgery. The median follow-up period until the time of writing this manuscript was 52 months (range 2-125). Histology slides were also reviewed in terms of the depth of invasion, degree of differentiation, lymphovascular invasion, and the presence or absence of multiple lesions. Lymphatic or venous invasion was evaluated on D2-40- or elastic van Gieson-stained sections, respectively. Tumor stages were defined based on the TNM classification system (UICC 7 th edition ${ }^{9}$ ).

\section{Immunohistochemistry}

Tissue microarray blocks were constructed using Tissue Microarrayer JF-3 (Pathology Institute, Toyama, Japan). Three representative tissue cores ( $2 \mathrm{~mm}$ in diameter) were obtained from each case. In addition to SOX2, CD133 and p63 were also immunostained in order to determine how the expression of SOX2 is correlated with the expression of other stem/basal cell markers.

Immunostaining for SOX2, CD133, p63, and D2-40 was performed on a Bond Max autostainer (Leica Microsystems, Wetzlar, Germany) according to the manufacturers' protocols. Deparaffinized sections were heat-treated using pH9.0 ER2 solution (Leica Microsystems) for $10 \mathrm{~min}$ and incubated with primary antibodies. The antibodies used were a rabbit monoclonal antibody against human SOX2 (clone SP76, dilution 1:100, Abcam, Cambridge, UK), mouse monoclonal antibody against human CD133 (clone 80B258, $5 \mu \mathrm{g} / \mathrm{ml}$, made in one of our laboratories ${ }^{10}$ ), mouse monoclonal antibody against p63 (clone 4A4, pre-diluted, Nichirei Bioscience, Tokyo, Japan), and mouse monoclonal antibody against D2-40 (clone D2-40, dilution 1/50, Dako Cytomation, Glostrup, Denmark). Positive controls were the normal prostate (SOX2), pancreas (CD133), and skin (p63 and D2-40) according to datasheets of antibodies and previous reports. ${ }^{10}$

Expression levels of SOX2, CD133, and p63 were evaluated semi-quantitatively according to the percentage of positive cells: negative (no expression); focal (1-25\%); moderate (26-50\%); extensive $(>50 \%)$. When all three cores were negative for SOX2, a whole section of cancer tissue was also stained in order to ensure that the expression of SOX2 was entirely absent in other regions. In patients with multiple esophageal cancers, the largest cancer was selected for tissue microarrays. When the largest tumor was SOX2-negative, the expression of SOX2 in all other lesions including intraepithelial neoplasia was also examined. Furthermore, in SOX2-negative cases, all metastatic deposits in lymph nodes dissected at the initial surgery and recurrent tumors biopsied during the follow-up were stained for SOX2 in order to eluci- 
date whether the expression of this transcriptional factor emerges during tumor progression.

\section{Gene Sequencing}

The DNA sequencing of SOX2 was performed in all SOX2-negative cases. Genomic DNA was extracted from formalin-fixed paraffin-embedded tissue blocks. Areas consisting of a large proportion of tumor cells $(>30 \%)$ were selected for DNA extraction under a microscope. DNA extraction was performed using the QIAamp DNA FFPE Tissue Kit (Qiagen, Hilden, Germany), following the manufacturer's instructions. DNA content was assessed using a NanoDrop 2000c spectrophotometer (Thermo Fisher Scientific, Waltham, MA, USA).

SOX2 contains a single exon (Gene ID 6657). Four sets of PCR primers were prepared to cover the entire exon. The promoter and $5^{\prime} / 3^{\prime}$-untranslated regions were also amplified using 3 and 8 sets of primers, respectively. Primer sequences are described in Supplementary Table 1. PCR was performed using $10-40 \mathrm{ng}$ of genomic DNA, $10 \mathrm{pmol}$ each of the forward and reverse primers (Hokkaido System Science, Hokkaido, Japan), and $15 \mu \mathrm{l}$ of GoTaq Green Master Mix 2x (Promega, Madison, WI, USA) in a total volume of $30 \mu \mathrm{l}$. The PCR thermocycling conditions used were as follows: $95^{\circ} \mathrm{C}$ for $1 \mathrm{~min}$, followed by 35 cycles of $95^{\circ} \mathrm{C}$ for $30 \mathrm{~s}, 56^{\circ} \mathrm{C}$ for $30 \mathrm{~s}$, and $72{ }^{\circ} \mathrm{C}$ for $1 \mathrm{~min}$. Amplification products were purified using the Wizard SV Gel and PCR Clean-Up System Kit (Promega). Cycle sequencing was performed using BigDye Terminator v3.1 (Applied Biosystems, Foster City, CA, USA) and the amplified products were separated by capillary electrophoresis on an ABI 3130xl Genetic Analyzer (Applied Biosystems).

\section{Fluorescent In Situ Hybridization}

Fluorescent in situ hybridization for SOX2 was performed in all SOX2-negative cases in order to elucidate whether SOX2-negative tumors have copynumber losses. The SOX2 target probe spanning the locus 3q26.33 (BAC clone CTD-2348H10, Invitrogen, Carlsbad, CA, USA) and a commercially available centromeric probe on chromosome 3 (Agilent Technologies, Santa Clara, CA, USA) were selected for hybridization. The copy-number per cell was enumerated on at least 50 tumor cells.

\section{Assessment of SOX2 Promoter Methylation}

The methylation status of the SOX2 promoter was analyzed as a potential epigenetic down-regulation mechanism of gene expression. Similar to other key developmental genes, which have high CpG density promoters, SOX2 contains an extensive CpG island before the transcription start site. ${ }^{11}$ Primer sequences for methylation-specific PCR were obtained from a previous study (Supplementary Table 1). ${ }^{12}$

The bisulfite modification of genomic DNA was performed using the EZ DNA methylation kit (Zymo Research, Irvine, CA, USA). In this process, unmethylated cytosine residues in genomic DNA are converted to uracil by sodium bisulfite. Methylationspecific PCR was performed using Takara EpiTaq HS (for bisulfite-treated DNA; Takara Bio, Shiga, Japan). The PCR thermocycling conditions used were as follows: $98^{\circ} \mathrm{C}$ for $1 \mathrm{~min}$, followed by 50 cycles of $98^{\circ} \mathrm{C}$ for $30 \mathrm{~s}, 51{ }^{\circ} \mathrm{C}$ for $30 \mathrm{~s}$, and $72^{\circ} \mathrm{C}$ for $30 \mathrm{~s}$. Reaction products were visualized by electrophoresis with ethidium bromide. The density of the bands was analyzed using ImageJ (version 1.41, National Institute of Health, Maryland) for semiquantification. The ratio of the density of methylated alleles to that of unmethylated ones was calculated for each sample.

\section{Statistical Analysis}

Continuous and categorical variables in each group were analyzed using an unpaired $t$-test, chi-squared test, and Fisher's exact test. The overall survival, disease-specific survival, and recurrence-free survival of patients were compared between SOX2positive and -negative cases using the Kaplan-Meier method, and differences between survival curves were evaluated with the Log-rank test. A multivariate analysis was also performed on prognostic factors assessed by Cox's proportional hazards model. A probability of $P<0.05$ was considered to be significant. The software used for statistical analyses was JMP ver.13 software (SAS Institute Inc, North Carolina, USA).

\section{Results}

SOX2 Expression in Squamous Cell Carcinomas of the Esophagus

SOX2 expression was retained in 105/113 (93\%) esophageal squamous cell carcinomas. Its expression was focal (1-25\% of cancer cells) in 3 cases, moderate $(26-50 \%)$ in 14 cases, and extensive $(>50 \%$ of cells) in 88 cases (Figure 1). The remaining 8 (7\%) appeared to be negative for this transcriptional factor in the tissue microarray study, and the complete loss of expression was further confirmed by additional staining on whole sections (Figure 1).

In SOX2-negative cases, the expression of this stemness molecule was completely lost even in intraepithelial areas, which was in clear contrast to the adjacent non-neoplastic epithelium, in which SOX2 was constantly expressed particularly in the lower $1 / 4$ to $3 / 4$ of the layer. Three out of eight SOX2-negative cases had intraepithelial neoplasia elsewhere of the esophagus (8 lesions; 1 to 6 lesions per case). Interestingly, all lesions were also 

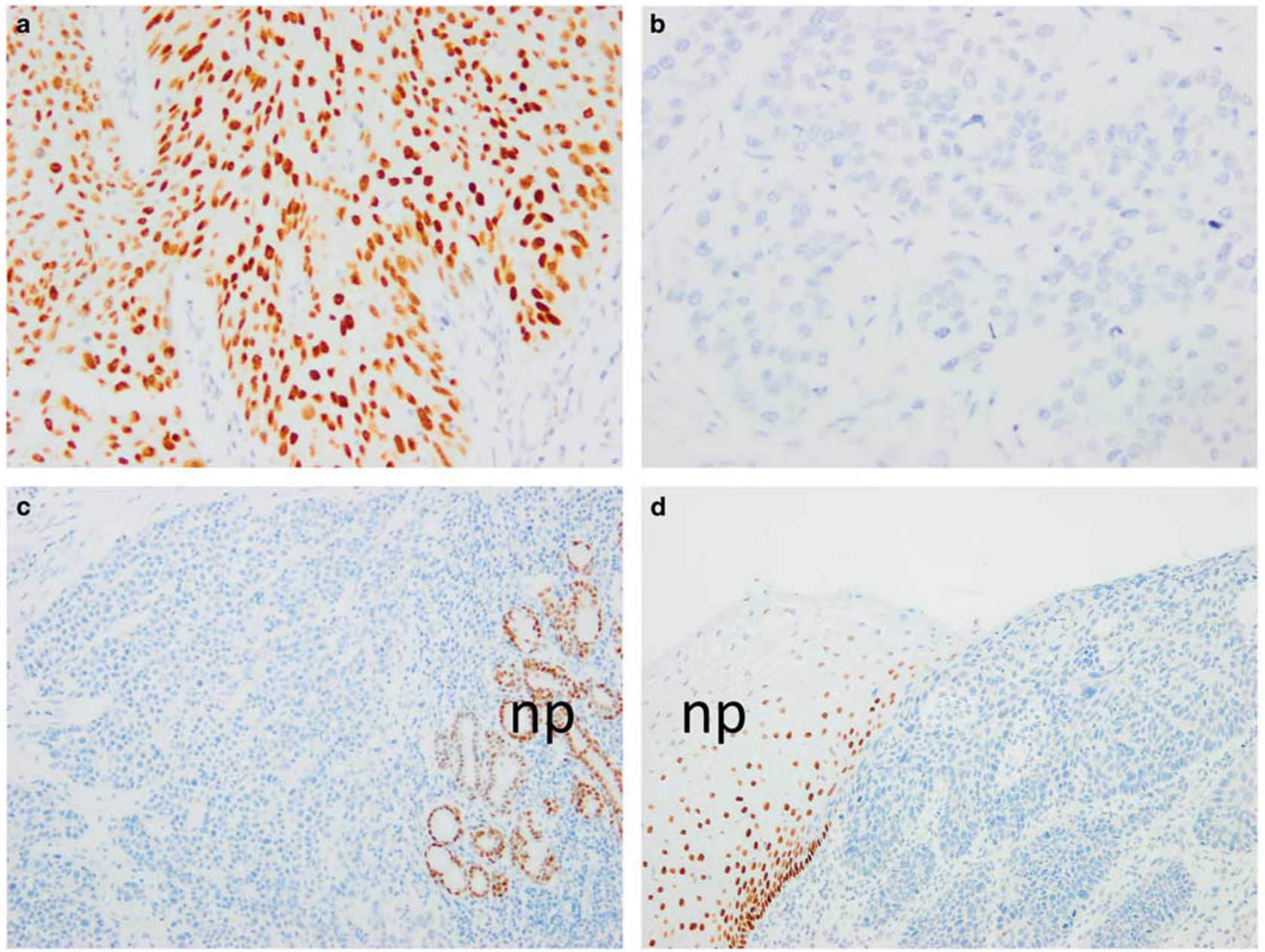

Figure 1 SOX2 immunostaining in squamous cell carcinomas of the esophagus. (a) SOX2 is diffusely expressed in cancer cells (a microarray section, $\times 200$ ). (b) No expression of SOX2 is observed (a microarray section, $\times 200$ ). (c) Although non-neoplastic esophageal glands (np) are positive for SOX2, cancer cells lack the expression of this transcriptional factor (a whole section, $\times 100$ ). (d) The lack of SOX2 expression in intraepithelial cancer (arrows) is in contrast to that in the SOX2-positive non-neoplastic epithelium (np).

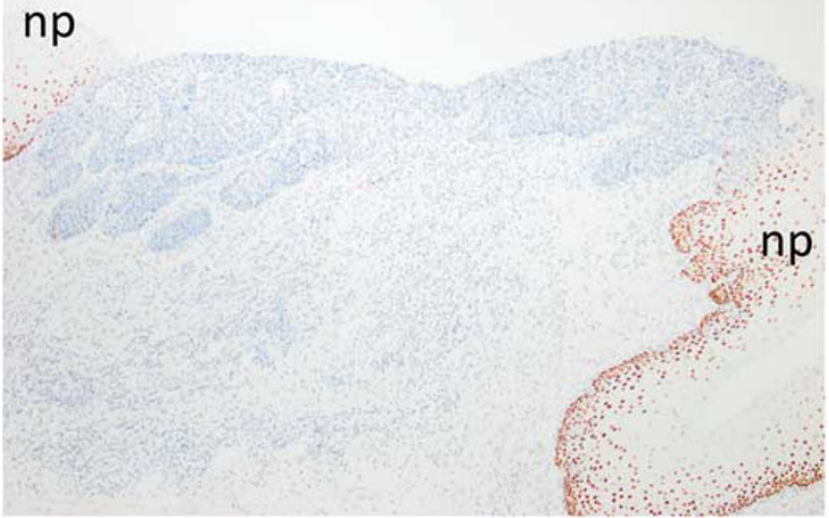

Figure 2 Complete loss of SOX2 expression in high-grade intraepithelial neoplasia observed in a case of SOX2-negative esophageal squamous cell carcinoma (patient 7). Although the non-neoplastic squamous epithelium (np) is positive for SOX2, high-grade intraepithelial neoplasia lacks its expression. SOX2 immunostaining, $\times 100$. completely SOX2 negative (Figure 2). In contrast, randomly selected separate dysplastic lesions $(n=10)$ in SOX2-positive cases expressed this transcriptional factor to variable degrees. SOX2 negativity was also confirmed in metastatic deposits in regional lymph nodes $(n=38)$ removed at the time of initial surgery and a recurrent tumor $(n=1)$ biopsied during the follow-up in SOX2-negative cases.

\section{Clinicopathologic Features}

The pathologic features of SOX2-negative esophageal cancers are summarized in Table 1. SOX2positive $(n=105)$ and -negative cases $(n=8)$ are compared hereafter. As shown in Table 2, no significant difference was observed between the two groups in terms of clinical features including age, gender, smoking and drinking histories, and serum tumor markers. Regarding pathologic parameters, SOX2-negative esophageal cancers were histologically less differentiated $(P=0.002)$ and 
Table 1 Pathologic features of SOX2-negative squamous cell carcinomas of the esophagus

\begin{tabular}{|c|c|c|c|c|c|c|c|}
\hline & $\begin{array}{l}\text { Age/ } \\
\text { Gender }\end{array}$ & Size & Gross appearance & Histology & $\begin{array}{l}\text { Lymphatic } \\
\text { infiltration }\end{array}$ & Multiple lesions & Stage \\
\hline Pt1 & $57 \mathrm{M}$ & $117 \mathrm{~mm}$ & Flat & $\begin{array}{l}\text { Poorly differentiated squamous cell carcinoma consisting of cancer } \\
\text { cells arranged in nests showing extensive intraepithelial spread. } \\
\text { Widespread lymphatic infiltration is observed in almost the entire } \\
\text { esophagus and gastric fundus. In addition to direct tumor invasion } \\
\text { down to the submucosal layer, marked lymphatic infiltration is noted } \\
\text { in the muscularis propria and adventitia (Figure 3). }\end{array}$ & Extensive & None & pT3N1M0 \\
\hline Pt2 & $62 \mathrm{M}$ & $110 \mathrm{~mm}$ & Flat & $\begin{array}{l}\text { Moderately differentiated squamous cell carcinoma with extensive } \\
\text { intraepithelial spread. Although direct invasion is restricted to the } \\
\text { lamina propria, widespread lymphatic infiltration is observed } \\
\text { throughout the esophageal wall. }\end{array}$ & Extensive & $\begin{array}{l}\text { Low-grade intraepithelial } \\
\text { neoplasia }(n=1)\end{array}$ & pT3N1M0 \\
\hline Pt3 & $60 \mathrm{M}$ & $80 \mathrm{~mm}$ & Ulcerative & $\begin{array}{l}\text { Poorly differentiated squamous cell carcinoma with tumor cells } \\
\text { arranged in a solid nested pattern. Lymphatic infiltration is observed } \\
\text { in an area distant from the tumor mass. }\end{array}$ & Extensive & None & pT3N1M0 \\
\hline Pt4 & $67 \mathrm{M}$ & $50 \mathrm{~mm}$ & Ulcerative & $\begin{array}{l}\text { A localized tumor consisting of moderately differentiated squamous } \\
\text { cell carcinoma. Cancer cells are arranged in a solid architecture. } \\
\text { Several foci of lymphatic infiltration are observed in remote areas. }\end{array}$ & Extensive & $\begin{array}{l}\text { High-grade intraepithelial } \\
\text { neoplasia }(n=1)\end{array}$ & pT2N1M0 \\
\hline Pt5 & $73 \mathrm{M}$ & $18 \mathrm{~mm}$ & Slightly elevated & $\begin{array}{l}\text { Poorly differentiated squamous cell carcinoma with cancer cells } \\
\text { arranged in solid sheets. Multiple foci of lymphatic invasion are } \\
\text { present, particularly at the invasive front. }\end{array}$ & Moderate & None & pT1NoM0 \\
\hline Pt6 & $84 \mathrm{~F}$ & $26 \mathrm{~mm}$ & Ulcerative & $\begin{array}{l}\text { Poorly differentiated squamous cell carcinoma consisting of tumor } \\
\text { cells arranged in a solid pattern with foci of borderline spindle cell } \\
\text { changes. Lymphatic invasion is present mainly inside the tumor mass. }\end{array}$ & Moderate & None & pT1NoM0 \\
\hline Pt7 & $61 \mathrm{~F}$ & $20 \mathrm{~mm}$ & Nodular & $\begin{array}{l}\text { Poorly differentiated squamous cell carcinoma with cancer cells } \\
\text { arranged in an irregular trabecular architecture shows scirrhous } \\
\text { infiltration. }\end{array}$ & Focal & $\begin{array}{l}\text { High-grade intraepithelial } \\
\text { neoplasia }(n=6)\end{array}$ & pT2N1M0 \\
\hline Pt8 & $72 \mathrm{M}$ & $85 \mathrm{~mm}$ & Ulcerative & $\begin{array}{l}\text { Moderately differentiated squamous cell carcinoma consisting of } \\
\text { sheeted tumor cells with occasional foci of keratinization. }\end{array}$ & Focal & None & pT3N1M0 \\
\hline
\end{tabular}


Table 2 Comparison of clinical features between SOX2-negative and -positive groups

\begin{tabular}{|c|c|c|c|}
\hline & SOX2 negative & SOX2 positive & \multirow{2}{*}{ P-value } \\
\hline & $(\mathrm{n}=8)$ & $(\mathrm{n}=105)$ & \\
\hline \multicolumn{4}{|l|}{ Age } \\
\hline Median & 65 & 66 & \multirow[t]{2}{*}{0.685} \\
\hline Range & $(57-84)$ & $(45-80)$ & \\
\hline \multicolumn{4}{|l|}{ Gender } \\
\hline Male & $6(75 \%)$ & 89 (85\%) & \multirow[t]{2}{*}{0.611} \\
\hline Female & $2(25 \%)$ & $16(15 \%)$ & \\
\hline \multicolumn{4}{|l|}{ Smoking } \\
\hline Non-smoker & $2(25 \%)$ & $17(16 \%)$ & \multirow[t]{3}{*}{0.658} \\
\hline Smoker & $6(75 \%)$ & $78(74 \%)$ & \\
\hline Unknown & 0 & $10(9 \%)$ & \\
\hline \multicolumn{4}{|l|}{ Drinking } \\
\hline Non-drinker & $1(13 \%)$ & $6(7 \%)$ & \multirow[t]{3}{*}{0.655} \\
\hline Drinker & $7(87 \%)$ & $89(84 \%)$ & \\
\hline Unknown & 0 & $10(9 \%)$ & \\
\hline \multicolumn{4}{|l|}{ Multiple lesions } \\
\hline Present & 3 (38\%) & $34(33 \%)$ & \multirow[t]{2}{*}{0.926} \\
\hline Absent & $5(62 \%)$ & $71(67 \%)$ & \\
\hline \multicolumn{4}{|c|}{ Tumor marker SCC } \\
\hline$\geq 1.5 \mathrm{ng} / \mathrm{ml}$ & $1(13 \%)$ & $36(34 \%)$ & \multirow[t]{3}{*}{0.269} \\
\hline$<1.5 \mathrm{ng} / \mathrm{ml}$ & $6(74 \%)$ & $64(61 \%)$ & \\
\hline Not measured & $1(13 \%)$ & $5(5 \%)$ & \\
\hline \multicolumn{4}{|c|}{ Tumor marker CEA } \\
\hline$\geq 5.0 \mathrm{ng} / \mathrm{ml}$ & 0 & $15(14 \%)$ & \multirow[t]{3}{*}{0.549} \\
\hline$<5.0 \mathrm{ng} / \mathrm{ml}$ & 7 (87\%) & $82(78 \%)$ & \\
\hline Not measured & $1(13 \%)$ & $8(8 \%)$ & \\
\hline
\end{tabular}

showed more advanced pT and pStages $(P=0.003$ and 0.007 , respectively) than SOX2-positive cases (Table 3). A remarkable histologic finding in SOX2negative cases was extensive lymphatic invasion. Widespread lymphatic infiltration distant from the primary invasive focus was observed in 4/8 (50\%) SOX2-negative cancers, but in none of the SOX2positive cases (Figure 3 ). In the remaining cases, lymphatic infiltration was focal ( $<5$ foci per section) or moderate (5-10 foci) (Table 1).

The relationship between SOX2 and CD133 (prominin-1) expression was examined in order to elucidate how the expression of these two stem cell markers are related. As shown in Table 4, although 7/8 (88\%) SOX2-negative cases lacked CD133 expression, 78/105 (74\%) SOX2-positive cancers were also negative for CD133 with no correlation between the two groups. No correlation was further observed between SOX2 and p63 (a marker for basal and para-basal cells) (Table 4).

\section{Post-Operative Outcome}

During the follow-up, tumor recurrence and cancerrelated death were more frequently observed in
Table 3 Comparison of pathologic features between SOX2negative and -positive groups

\begin{tabular}{|c|c|c|c|}
\hline & $\begin{array}{c}\text { SOX2 } \\
\text { negative }\end{array}$ & $\begin{array}{c}\text { SOX2 } \\
\text { positive }\end{array}$ & \multirow{2}{*}{ P-value } \\
\hline & $(\mathrm{n}=8)$ & $(\mathrm{n}=105)$ & \\
\hline \multicolumn{4}{|l|}{ Tumor size } \\
\hline Median & $65 \mathrm{~mm}$ & $33 \mathrm{~mm}$ & 0.270 \\
\hline Range & $18-117 \mathrm{~mm}$ & $5-140 \mathrm{~mm}$ & \\
\hline \multicolumn{4}{|l|}{ Location } \\
\hline Cervical & $1(13 \%)$ & $4(4 \%)$ & 0.016 \\
\hline Thoracic & $5(62 \%)$ & $98(93 \%)$ & \\
\hline Abdominal & 0 & $3(3 \%)$ & \\
\hline Diffuse & $2(25 \%)$ & 0 & \\
\hline \multicolumn{4}{|l|}{ Degree of differentiation } \\
\hline Well to moderately & $3(38 \%)$ & $101(89 \%)$ & 0.002 \\
\hline Poorly & $5(62 \%)$ & $12(11 \%)$ & \\
\hline \multicolumn{4}{|l|}{ Vascular invasion } \\
\hline Present & $6(75 \%)$ & $31(30 \%)$ & 0.014 \\
\hline Absent & $2(25 \%)$ & $74(70 \%)$ & \\
\hline \multicolumn{4}{|l|}{ Lymphatic invasion } \\
\hline Present & $8(100 \%)$ & $50(48 \%)$ & $<0.001$ \\
\hline Absent & 0 & $55(52 \%)$ & \\
\hline \multicolumn{4}{|l|}{$p T$ classification } \\
\hline pT1 & $2(25 \%)$ & $82(78 \%)$ & 0.003 \\
\hline pT2-4 & $6(75 \%)$ & $23(22 \%)$ & \\
\hline \multicolumn{4}{|l|}{ Lymph node metastasis } \\
\hline Present & $6(75 \%)$ & $70(67 \%)$ & 0.026 \\
\hline Absent & $2(25 \%)$ & $35(33 \%)$ & \\
\hline \multicolumn{4}{|l|}{ pStage } \\
\hline pStage I & $2(25 \%)$ & $64(61 \%)$ & 0.007 \\
\hline pStages II-IV & $6(75 \%)$ & $41(39 \%)$ & \\
\hline \multicolumn{4}{|l|}{ Recurrence } \\
\hline Present & $5(62 \%)$ & $18(17 \%)$ & 0.009 \\
\hline Absent & $3(38 \%)$ & $87(83 \%)$ & \\
\hline Disease-specific mortality & $4(50 \%)$ & $8(8 \%)$ & 0.004 \\
\hline
\end{tabular}

SOX2-negative cases than in SOX2-positive cancers $(P=0.009$ and 0.004 , respectively) (Table 2). Five patients developed recurrence by the time of writing this manuscript in the abdominal lymph nodes $(n=5)$, parabronchial lymph nodes $(n=1)$, an anastomotic site $(n=1)$, the liver $(n=1)$, bone $(n=1)$, and/or duodenum $(n=1)$. The recurrent tumor in the duodenum presented with a slightly elevated mucosal lesion, a biopsy from which showed cancer cells in dilated lymphatics of the lamina propria, but no infiltration outside the vessels (Figure 4).

Recurrence-free and disease-specific survival were significantly shorter in patients with SOX2-negative esophageal cancer than in patients with SOX2positive malignancy (both $P<0.001$ ) (Figure 5). The median recurrence-free survival was 11 months for SOX2-negative cases and 51 months for the SOX2-positive group. In order to elucidate whether the lack of SOX2 expression is an independent 

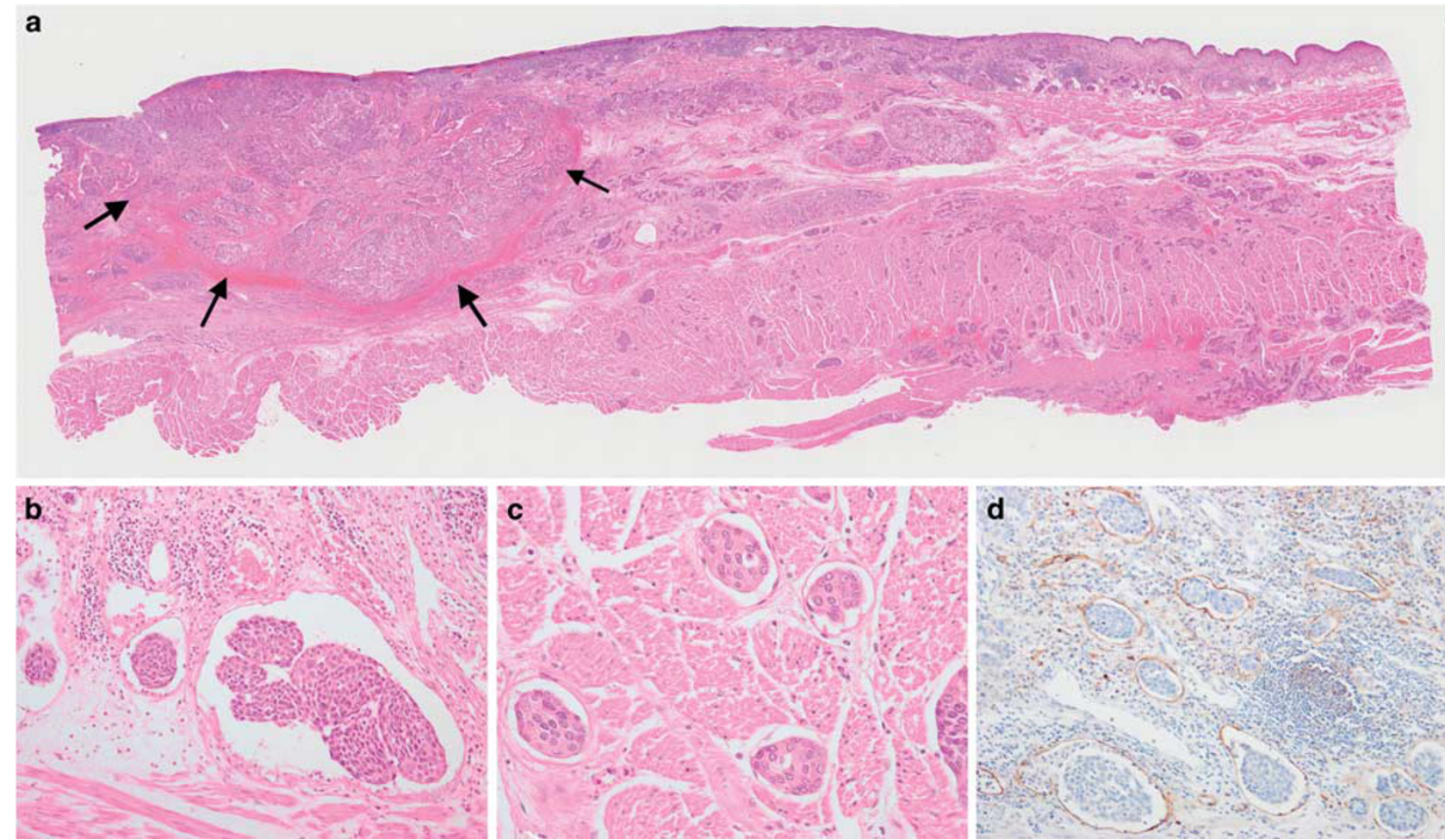

Figure 3 Extensive lymphatic infiltration in a case of SOX2-negative esophageal squamous cell carcinoma (patient 1). (a) Overview of the tissue with cancer cells adjacent to primary invasive focus (arrows) and remote stroma observed mainly inside lymphatics (H\&E). (b) Tumor cell nests are observed in dilated lymphatics in the lamina propria $(\mathrm{H} \& \mathrm{E}, \times 200)$. (c) Lymphatic invasion is observed in the muscularis propria $(\mathrm{H} \& \mathrm{E}, \times 200)$. (d) Immunostaining for D2-40 highlights vascular structures lined by endothelial cells around tumor cell nests $(\times 100)$.

Table 4 Relationship between the expression of SOX2 and CD133 or p63 in squamous cell carcinomas of the esophagus*

\begin{tabular}{|c|c|c|c|c|}
\hline & \multicolumn{4}{|c|}{ CD133 } \\
\hline & Negative & Focal & Moderate & Extensive \\
\hline \multicolumn{5}{|l|}{ SOX2 } \\
\hline Negative & 7 & 1 & 0 & 0 \\
\hline Focal & 2 & 1 & 0 & 0 \\
\hline Moderate & 6 & 5 & 2 & 1 \\
\hline \multirow[t]{3}{*}{ Extensive } & 70 & 10 & 4 & 4 \\
\hline & \multicolumn{4}{|c|}{ p63 } \\
\hline & 0 & $1+$ & $2+$ & $3+$ \\
\hline \multicolumn{5}{|l|}{ SOX2 } \\
\hline Negative & 0 & 1 & 0 & 7 \\
\hline Focal & 0 & 0 & 1 & 2 \\
\hline Moderate & 0 & 1 & 0 & 13 \\
\hline Extensive & 0 & 4 & 2 & 82 \\
\hline
\end{tabular}

Negative, no expression; focal, positive in $1-25 \%$ of cancer cells, moderate, $26-50 \%$; extensive, $>50 \%$. *No correlation found in either comparison $(P>0.05)$.

prognostic factor, a multivariate analysis was performed with the application of two other potential prognostic factors (pT classification and lymph node metastasis). Cox's proportional hazards model identified the loss of SOX2 expression and nodal metastasis as independent poor prognostic factors for disease-specific survival (Table 5).

\section{Gene Sequencing and Fluorescent In Situ Hybridization of SOX2}

The entire exon, promoter, and $5^{\prime} / 3^{\prime}$-untranslated regions were successfully sequenced in all SOX2negative cases using multiple sets of primers. All SOX2-negative cancers appeared to have the wildtype genotype. Fluorescent in situ hybridization was also conducted for the assessment of copy-number variations in SOX2-negative cancers. The numbers of SOX2 and centromere signals were similar in all cases, suggesting no copy-number loss of SOX2.

\section{Promoter Methylation Assay}

As neither mutations nor copy-number losses were found in SOX2, the loss of SOX2 expression was likely due to epigenetic gene silencing. Then, the methylation status of the SOX2 promoter domain was compared between SOX2-negative $(n=8)$ and -positive cases $(n=4)$. SOX2-positive cases were selected from samples with SOX2 immuno-expression. As shown in Figure 6, methylated alleles were 

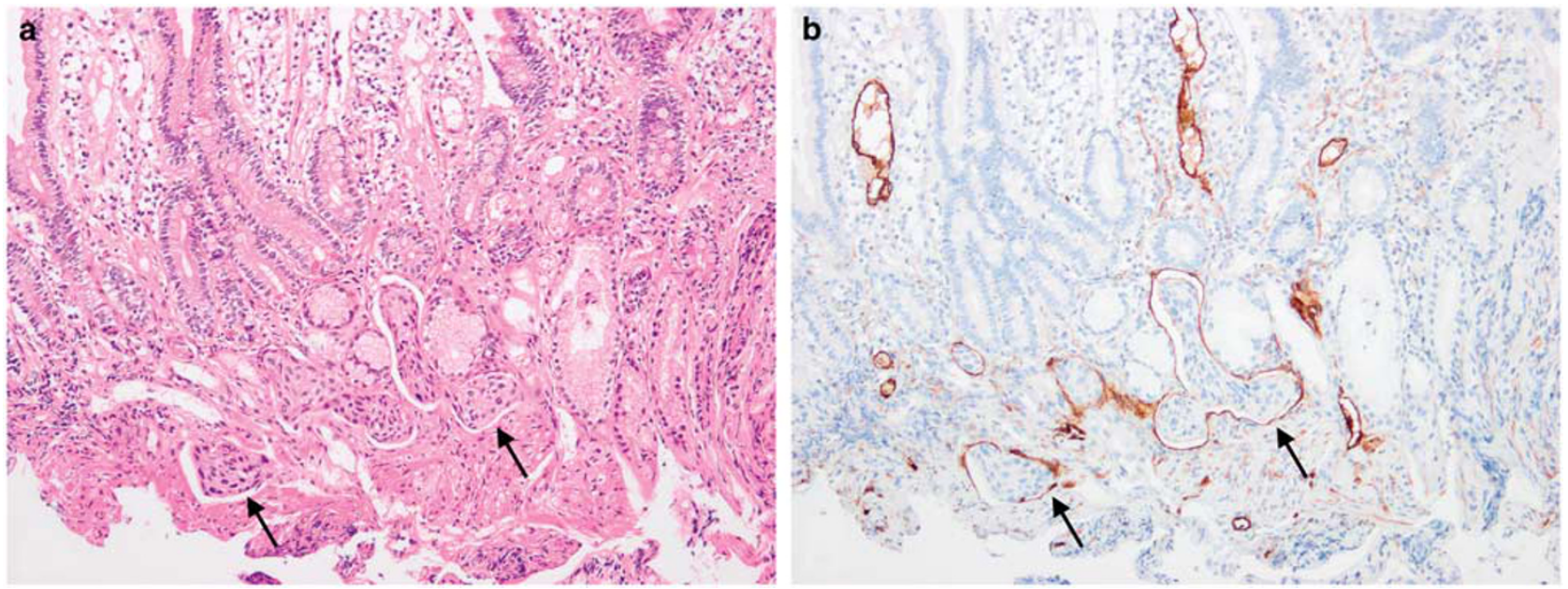

Figure 4 Duodenal biopsy from mucosal elevation detected during the follow-up (patient 2). (a) Tumor cell nests are observed in the lamina propria (arrows) (H\&E, $\times 100$ ). (b) Immunostaining for D2-40 confirms that cancer cells are located inside lymphatics (arrows) $(\times 100)$.
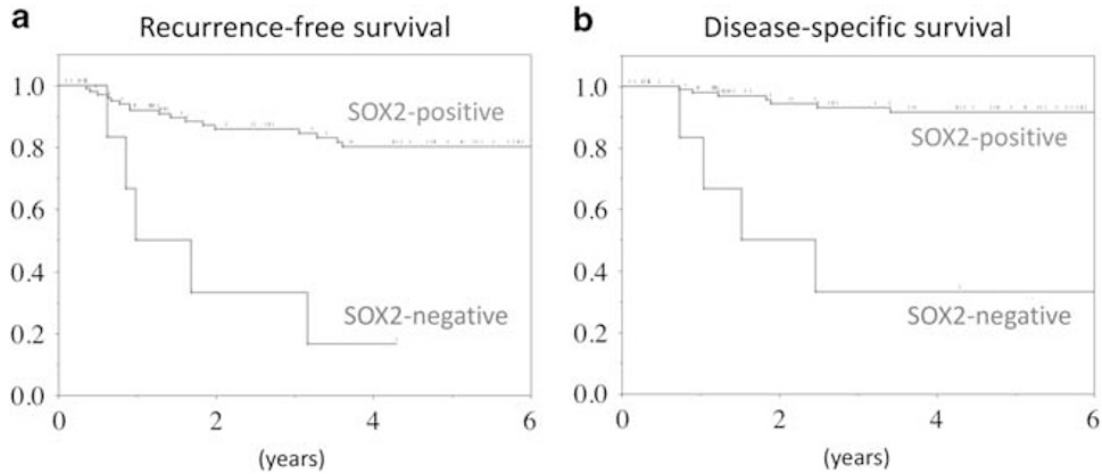

Figure 5 Post-operative survival curves of SOX2-positive and -negative cases. Patients with SOX2-negative esophageal cancer show significantly shorter recurrence-free (a) and disease-specific survival (b) than those with SOX2-positive malignancy $(P<0.001$ and $P=0.002$, respectively).

Table 5 A multivariate analysis for disease-specific survival

\begin{tabular}{lcc}
\hline & OR $(95 \%$ CI) & P-value \\
\hline $\begin{array}{l}\text { SOX2 expression } \\
\text { Negative vs positive }\end{array}$ & $7.05(1.27-39.0)$ & 0.025 \\
$\begin{array}{c}\text { pT classification } \\
\text { pT1 vs pT2-4 }\end{array}$ & $1.28(0.12-12.7)$ & 0.830 \\
$\begin{array}{c}\text { Lymph node metastasis } \\
\text { Present vs absent }\end{array}$ & $8.35(1.53-45.3)$ & 0.014 \\
\hline
\end{tabular}

observed in all SOX2-negative cases, but were scarce in SOX2-positive cancers. A semi-quantitative imaging analysis also revealed that the expression ratio of methylated to unmethylated alleles in SOX2negative cancers was significantly higher than that in SOX2-positive cases, suggesting that SOX2 promoter hypermethylation is a distinct molecular feature for SOX2-negative cancers.

\section{Discussion}

The results obtained in the present study are summarized as follows: (i) unlike the non-neoplastic squamous epithelium and most cases of esophageal cancers, a subset of esophageal squamous cell carcinomas $(7 \%)$ completely lacked the expression of SOX2; (ii) SOX2-negative cancers were characterized by advanced stages and extensive lymphatic infiltration; (iii) multiple neoplastic lesions observed in SOX2-negative cases also lacked the expression of this transcriptional factor; (iv) the loss of SOX2 expression was an independent poor prognostic factor for patients with esophageal squamous cell carcinoma, and (v) SOX2 promoter hypermethylation appeared to be a cause of SOX2 silencing.

SOX2-negative squamous cell carcinomas of the esophagus had several unique histopathologic features. Lymphatic infiltration was observed in all patients, and was particularly extensive in 4/8 cases. One of these cases had recurrent cancer in the duodenum with mucosal elevation consisting of 
a
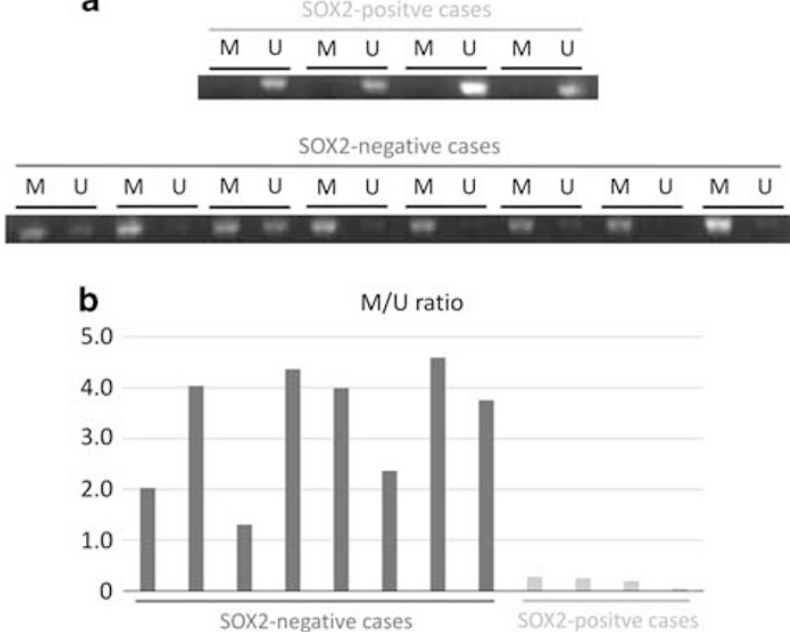

Figure 6 Methylation-specific PCR analysis of the SOX2 promoter. (a) PCR products recognizing unmethylated (U) and methylated (M) CpG sites were analyzed in SOX2-positive $(n=4)$ and -negative $(n=8)$ squamous cell carcinomas of the esophagus. Methylated products are observed in all SOX2-negative cases, but are scarce in SOX2-positive cancers. (b) The semi-quantitative imaging analysis reveals that methylated/unmethylated $(\mathrm{M} / \mathrm{U})$ ratios in SOX2negative cases are significantly higher than those in SOX2negative cancers $(P=0.008)$

intra-lymphatic cancer cells. Similar to the present results, a previous study suggested that the stronger expression of SOX2 negatively correlated with lymph node metastasis in squamous cell carcinomas of the esophagus. ${ }^{13}$ In addition, all multiple neoplastic lesions that developed in SOX2-negative cases lacked SOX2 expression. This result may suggest that patients with SOX2-negative esophageal cancer have a susceptibility to this minor form of esophageal cancer. Furthermore, SOX2 expression was already lost in intraepithelial neoplasia, indicating that the silencing of this gene participates in the early phase of carcinogenesis. Lastly, the expression of SOX2 did not correlate with that of other biomarkers such as stem and cancer stem cell antigen CD133 or basal cell marker p63. ${ }^{14}$ Therefore, the lack of SOX2 expression does not simply represent the loss of the stem/basal cell phenotype.

A potential relationship between SOX2 expression and patient prognoses has been investigated in the most detail in squamous cell carcinomas of the lungs. The prognostic impact of the amplification of SOX2 was not confirmed in two separate studies on pulmonary squamous cell carcinomas, while its overexpression on immunohistochemistry correlated with a better prognosis in other multiple cohorts. ${ }^{8,15-17}$ Findings obtained for esophageal squamous cell carcinomas are more limited and not conclusive. Although the index study suggested that the stronger expression of SOX2 was associated with higher tumor grades and poorer prognoses, ${ }^{5}$ subsequent studies did not validate these findings. ${ }^{6,7}$ One potential cause for discrepant findings is that different cut-off points were used for SOX2 phenotyping. Our standard, in which only complete loss was defined as SOX2-negative, is the most stringent. SOX2 expression was also lost in $\approx 20 \%$ of esophageal adenocarcinomas, and negative expression was associated with a poor prognosis. ${ }^{18}$

According to the database cBioPortal (http://www. cbioportal.org/index.do), various malignant tumors have been found to harbor SOX2 mutations, which randomly occur with no specific hot points. The highest incidence of SOX2 mutations was observed in malignant melanoma (4\%), followed by gastric cancer $(3 \%)$, and cervical cancer $(2 \%)$. SOX2mutated adenocarcinomas of the esophagus have also been reported. As SOX2 mutations are observed in various cancers, gene mutations were initially considered to be a potential cause of SOX2 silencing in our study cohort. However, coding and noncoding regions were both the wild type in all SOX2negative cases. SOX2-mutated squamous cell carcinomas of the esophagus were also not found in the database or a recent whole-exome sequencing study, ${ }^{19}$ suggesting that SOX2 mutations are exceptional, even if they occur, in squamous cell carcinomas of the esophagus. The present study also indicated that copy-number loss was unlikely to be a cause of $S O X 2$ silencing.

Previous studies investigated SOX2 promoter methylation in human malignant tumors. For instance, Wong and colleagues examined the methylation status of the SOX2 promoter region in 72 endometrial carcinomas and found methylated alleles in $38 \%$ of cases. ${ }^{20}$ Similar to the present study, SOX2 methylation correlated with the shorter survival of patients with endometrial cancer. ${ }^{20}$ Otsubo et al also reported that SOX2 was hypermethylated in 12/74 (16\%) gastric cancers, and methylation-positive cases showed significantly worse prognoses than methylation-negative cases. ${ }^{21}$ Taken together, the hypermethylation of SOX2 in cancers appears to consistently correlate with an aggressive clinical course and poor prognosis. However, the effects of SOX2 silencing may differ in mesenchymal cells. Alonso et al performed methylation-specific PCR on glioblastomas, and found that the SOX2 promoter was hypomethylated in all patient samples relative to normal cell lines. ${ }^{22}$ SOX2 was overexpressed in glioblastomas at both the protein and mRNA levels. In addition, ectopic SOX2 expression induced the invasion and migration of glioma cells. ${ }^{22}$

Since the expression of SOX2 is considered to stimulate cellular proliferation, migration, invasion, and tumor metastasis in various human malignancies (eg, lung, esophageal, colorectal, prostate, and breast cancers), ${ }^{23-26}$ it remains unclear why the loss of SOX2 expression is associated with highly malignant clinical phenotypes. One in vitro study reported that the exogenous expression of SOX2 suppressed cell proliferation in normal and malignant gastric epithelial cell lines. ${ }^{21}$ A flow cytometry 
analysis revealed that SOX2-overexpressing cells exhibited cell-cycle arrest and apoptosis, along with the weaker expression of cyclin D1 and phosphorylated $\mathrm{Rb}$, and an increased p27 level. ${ }^{21}$ Therefore, SOX2-silenced cancer cells may escape cell-cycle arrest and become resistant to apoptosis.

In conclusion, SOX2-silenced squamous cell carcinomas of the esophagus appeared to be a minor, but distinct form of malignancy, characterized by extensive lymphatic invasion, a poor prognosis, and the development of multiple SOX2-negative neoplastic lesions. Hypermethylation of the promoter region was determined to be a critical epigenetic event leading to $S O X 2$ silencing.

\section{Disclosure/conflict of interest}

The authors declare no conflict of interest.

\section{References}

1 Rustgi AK, El-Serag HB. Esophageal carcinoma. N Engl J Med 2014;371:2499-2509.

2 Pennathur A, Gibson MK, Jobe BA, et al. Oesophageal carcinoma. Lancet 2013;381:400-412.

3 Pennathur A, Farkas A, Krasinskas AM, et al. Esophagectomy for T1 esophageal cancer: outcomes in 100 patients and implications for endoscopic therapy. Ann Thorac Surg 2009;87:1048-1054.

4 Fong H, Hohenstein KA, Donovan PJ. Regulation of selfrenewal and pluripotency by Sox2 in human embryonic stem cells. Stem Cells 2008;26:1931-1938.

5 Bass AJ, Watanabe $\mathrm{H}$, Mermel $\mathrm{CH}$, et al. SOX2 is an amplified lineage-survival oncogene in lung and esophageal squamous cell carcinomas. Nat Genet 2009;41: 1238-1242.

6 Gen Y, Yasui K, Zen Y, et al. SOX2 identified as a target gene for the amplification at 3q26 that is frequently detected in esophageal squamous cell carcinoma. Cancer Genet Cytogenet 2010;202:82-93.

7 Maier S, Wilbertz T, Braun M, et al. SOX2 amplification is a common event in squamous cell carcinomas of different organ sites. Hum Pathol 2011;42:1078-1088.

8 Wilbertz T, Wagner P, Petersen K, et al. SOX2 gene amplification and protein overexpression are associated with better outcome in squamous cell lung cancer. Mod Pathol 2011;24:944-953.

9 Sobin LH, Gospodarowicz MK, Wittekind C, et al. TNM Classification of Malignant Tumours, 7th ed. Wiley-Blackwell: Chichester, West Sussex, UK; Hoboken, NJ, 2010.

10 Karbanová J, Missol-Kolka E, Fonseca AV, et al. The stem cell marker CD133 (Prominin-1) is expressed in various human glandular epithelia. J Histochem Cytochem 2008;56:977-993.
11 Wegner $M$. From head to toes: the multiple facets of Sox proteins. Nucleic Acids Res 1999;27: 1409-1420.

12 Li AS, Siu MK, Zhang H, et al. Hypermethylation of SOX2 gene in hydatidiform mole and choriocarcinoma. Reprod Sci 2008;15:735-744.

13 Chuang WY, Chang YS, Chao YK, et al. High sex determining region Y-box 2 (SOX2) expression correlates with absence of nodal metastasis in esophageal squamous cell carcinoma. Int J Clin Exp Pathol 2015;8: 9248-9255.

14 Grosse-Gehling P, Fargeas CA, Dittfeld C, et al. CD133 as a biomarker for putative cancer stem cells in solid tumours: limitations, problems and challenges. J Pathol 2013;229:355-378.

15 Chen Y, Huang Y, Huang Y, et al. The prognostic value of SOX2 expression in non-small cell lung cancer: a meta-analysis. PLoS One 2013;8:e71140.

16 Brcic L, Sherer CK, Shuai Y, et al. Morphologic and clinicopathologic features of lung squamous cell carcinomas expressing Sox2. Am J Clin Pathol 2012; 138:712-718.

17 Velcheti V, Schalper K, Yao X, et al. High SOX2 levels predict better outcome in non-small cell lung carcinomas. PLoS One 2013;8:e61427.

18 Honing J, Pavlov KV, Meijer C, et al. Loss of CD44 and SOX2 expression is correlated with a poor prognosis in esophageal adenocarcinoma patients. Ann Surg Oncol 2014;21:S657-S664.

19 Song Y, Li L, Ou Y, et al. Identification of genomic alterations in oesophageal squamous cell cancer. Nature 2014;509:91-95.

20 Wong OG, Huo Z, Siu MK, et al. Hypermethylation of SOX2 promoter in endometrial carcinogenesis. Obstet Gynecol Int 2010;2010.

21 Otsubo T, Akiyama Y, Yanagihara K, et al. SOX2 is frequently downregulated in gastric cancers and inhibits cell growth through cell-cycle arrest and apoptosis. Br J Cancer 2008;98:824-831.

22 Alonso MM, Diez-Valle R, Manterola L, et al. Genetic and epigenetic modifications of Sox2 contribute to the invasive phenotype of malignant gliomas. PLoS One 2011;6:e26740.

$23 \mathrm{Li} \mathrm{J,} \mathrm{Du} \mathrm{L,} \mathrm{Yang} \mathrm{Y,} \mathrm{et} \mathrm{al.} \mathrm{MiR-429} \mathrm{is} \mathrm{an} \mathrm{independent}$ prognostic factor in colorectal cancer and exerts its anti-apoptotic function by targeting SOX2. Cancer Lett 2013;329:84-90.

24 Jia X, Li X, Xu Y, et al. SOX2 promotes tumorigenesis and increases the anti-apoptotic property of human prostate cancer cell. J. Mol Cell Biol 2011;3: 230-238.

25 Leis O, Eguiara A, Lopez-Arribillaga E, et al. Sox2 expression in breast tumours and activation in breast cancer stem cells. Oncogene 2012;31:1354-1365.

26 Gen Y, Yasui K, Nishikawa T, et al. SOX2 promotes tumor growth of esophageal squamous cell carcinoma through the AKT/mammalian target of rapamycin complex 1 signaling pathway. Cancer Sci 2013;104: 810-816.

Supplementary Information accompanies the paper on Modern Pathology website (http://www.nature.com/ modpathol) 